\title{
Ageing, infecundity and reproductive senescence in free-ranging female rhesus monkeys
}

\author{
R. L. Johnson ${ }^{1,2}$ and E. Kapsalis ${ }^{1}$ \\ ${ }^{1}$ Department of Anthropology, State University of New York, Buffalo, NY 14261, USA; and \\ ${ }^{2}$ Department of Biology, Florida Keys Community College, Key West, FL 33040, USA
}

\begin{abstract}
The reproductive performance of 760 free-ranging female rhesus monkeys (Macaca mulatta), 168 of whom were 20 years of age and older at the time observations were begun, was assessed. The monkeys were resident on Raccoon Key or Key Lois, two islands located in the Florida Keys, USA. During 1992 and 1993, live birth rates generally declined with age among the Raccoon and Lois females aged eight years and older. This age-related deterioration of female fertility was the result of proportionately more younger females bearing live young during successive birth seasons, and proportionately more older females experiencing an inability to bear live offspring even after a barren year. It is suggested that (1) older females may be more strongly inhibited by the suckling stimulus than are their younger peers, and (2) the risk of a permanent loss of fecundity increases with each additional year of life or parturition. The live birth rates of females aged 16-24 years were greater on Raccoon Key than they were on Key Lois, because the Raccoon females within this age range were more successful at bearing live offspring during successive birth seasons; the reason for this difference could not be determined. Inter-population differences in both the body condition of the females and the severity of female-female competition for access to males were not considered to be plausible explanations. It is possible that the difference in female fertility between the islands is the result of the greater age of the adult males on Key Lois, or the phytochemicals eaten by the females on Raccoon Key.
\end{abstract}

\section{Introduction}

Reproductive senescence in female non-human primates has been the focus of several studies over the past two decades. The attention focused on this topic has been due in part to the desire to identify a suitable animal model for the study of the menopause (see Walker, 1995). The studies conducted to date typically have included fewer than 12 older animals as subjects and, thus, have suffered the disadvantage of a small sample size. Females within the primate genus Macaca are unequivocally old by the time they are 20 years of age (see Hodgen et al, 1977; Hrdy, 1981; Paul et al,, 1993), and have been characterized as 'extremely' old (Fedigan, 1991) by the time they are 25 years old. Data are presented here on the reproductive performance of over 760 free-ranging female rhesus monkeys (Macaca mulatta), 168 of whom were 20-24 years old at the time this study was begun.

Our use of the terms fertility and fecundity closely follows that of human demographers (e.g., Menken et al., 1986; Biggers, 1988; Johnson et al., 1990). Specifically, 'fertility' is used here interchangeably with 'reproductive performance' with both referring to the actual production of live offspring by rhesus females. 'Fecundity', on the other hand, is used to refer to the capacity of individual females to conceive and deliver live young. A related term, 'infecundity', here refers to a

Revised manuscript received 5 July 1995. substantially diminished (but not wholly absent) ability to produce a live-birth conception.

Rhesus females are not fecund throughout the year since ovulatory cycles accompanied by copulations are restricted to the annual mating season (Gordon, 1981; Wilson et al., 1982). Because birth-season fertility is directly observable in freeranging rhesus but mating-season fecundity is not, the former was examined to draw inferences about age-related variation in the latter. With the large sample of rhesus females, both young and old, we are able to show that (1) profound inter-population differences in the rate at which fertility declines with age are possible, and (2) females surviving to age 20 within provisioned populations are likely to remain fecund well into their third decade of life.

\section{Materials and Methods}

\section{Study sites and populations}

Key Lois is an island of 39 hectares located at $24^{\circ} 36^{\prime} 5^{\prime \prime} \mathrm{N}$, $81^{\circ} 28^{\prime} 32^{\prime \prime} \mathrm{W}$ in the Atlantic Ocean. Raccoon Key is about 81 hectares in area and situated nearly $9 \mathrm{~km}$ to the north, at $24^{\circ} 44^{\prime} 45^{\prime \prime} \mathrm{N}, 81^{\circ} 29^{\prime} 32^{\prime \prime} \mathrm{W}$ in the Gulf of Mexico. The dominant vegetation on both islands is red mangrove (Rhizophora mangle) and black mangrove (Avicennia germinans). Other plant species are only sparsely distributed on Key Lois, but are 
relatively abundant on Raccoon Key. They include, but are not limited to, saltwort (Batis maritima) sea oxeye (Borrichia orborescens), sea daisy (Borrichia frutescens), morning glory (Ipomea sp.), white mangrove (Laguncularia racemosa), buttonwood (Conocarpus erecta) and key thatch-palm (Thrinax morrisii). Observational conditions on both islands are difficult with deep mud and brackish water covering large areas, making them inaccessible to observers (Johnson, 1989).

Over 1200 female and 170 male rhesus monkeys were released on Key Lois from 1973 to 1976 (Sherman, 1980; Pucak ef al, 1982). The animals originated from the Himalayan foothills of India, and were nearly all juveniles or young adults (i.e., 2-4 years of age) at the time of their entry into the USA (Sherman, 1980). Each was assigned an estimated year of birth upon arrival. There were only a few births on the island in 1974 owing to the relative immaturity of the animals imported; reproduction began in earnest in 1975. From 1978 to 1980, over 500 of the Key Lois rhesus, including both Indian- and island-born animals, were removed and transferred to Raccoon Key. From their inception, the Raccoon and Lois populations have been provided daily with both fresh water and a commercial primate diet.

The annual birth season on Raccoon Key and Key Lois begins in late January to March and ends in late September to early November. Contrary to the findings of a recent study by Lehman et al. (1994) that was based primarily on incomplete colony records, we found that births on both islands peak in early to mid-May; in 1992 and 1993, almost 40\% of all births occurred during this month (R. L. Johnson and E. Kapsalis, unpublished data). Given the timing of the birth season on the islands, and given that gestation in rhesus monkeys averages 167 days (Silk et al., 1993), it follows that conceptions on Raccoon Key and Key Lois occur between late August and early May, but are most common from mid-November to mid-December when copulatory behaviour peaks ( $R$. L. Johnson and E. Kapsalis, unpublished data).

Soon after their establishment on the islands, the periodic removal of animals for sale became a permanent feature of the management regimen of both colonies. Some adult females (individuals $\geq 4$ years old) have occasionally been removed from Key Lois and Raccoon Key; but at no time has there been an effort to identify and remove less productive females from either colony. In fact, the overwhelming majority of the monkeys removed each year are animals born the previous calendar year, that is, 'yearlings' 9-18 months of age. The annual removal of these monkeys begins in late January or early February (when copulatory activity is in decline) and continues intermittently until the following autumn. Thus, for those females that give birth two years in a row, the loss of a yearling through trapping typically occurs only after they have already conceived their second offspring.

\section{Census methods and population demography}

The data reported here were collected during a continuous 2 year census of the Key Lois and Raccoon Key monkeys that began in February 1992 and ended in January 1994. Our field methods were modelied after those used by Johnson (1989) during the last extended census of the Key Lois and Raccoon
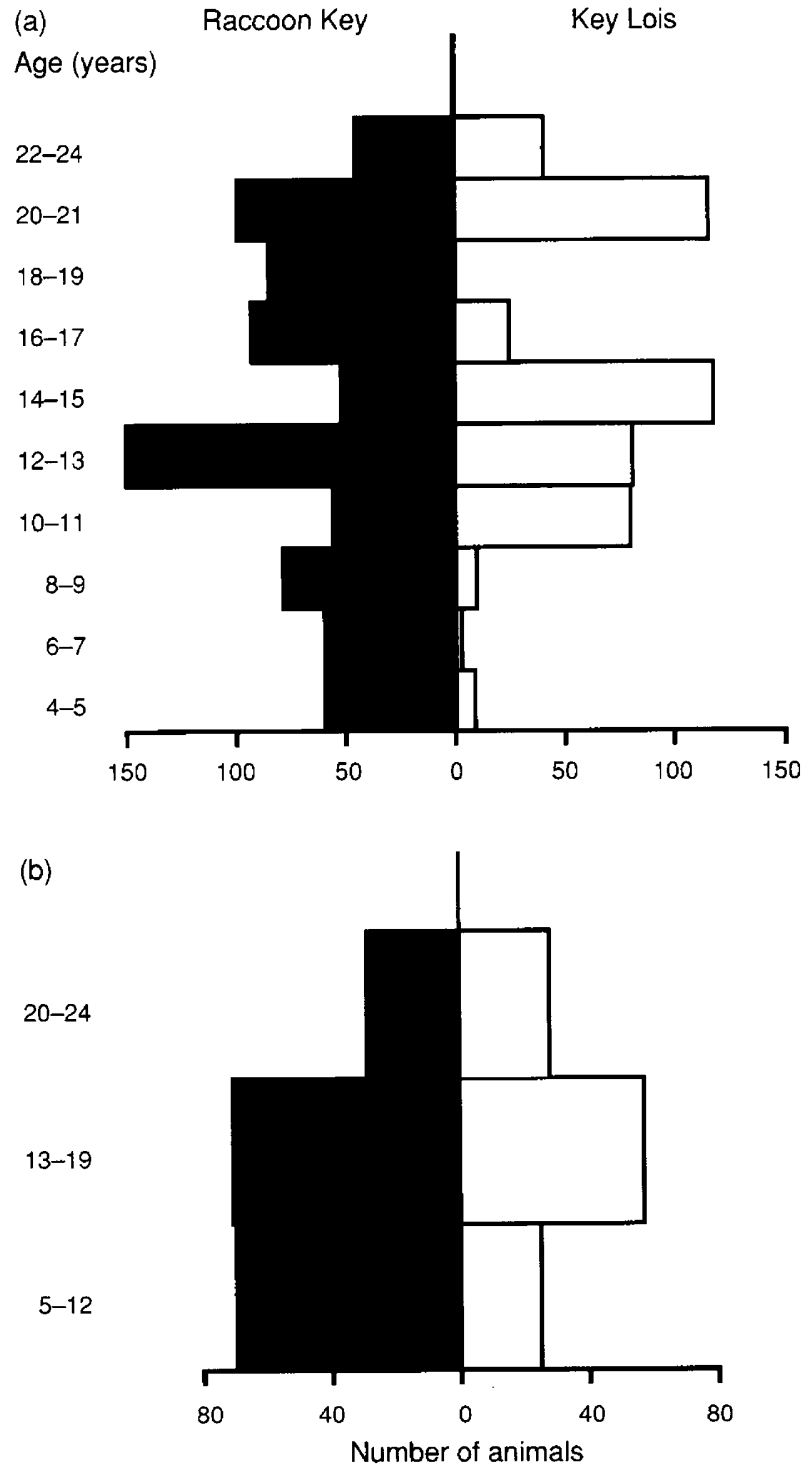

Fig. 1. Age distribution of (a) adult female rhesus monkeys and (b) adult males on ( $\square$ ) Raccoon Key and ( $\square$ ) Key Lois as of the beginning of 1992 .

Key rhesus monkeys. Specifically, each island was visited two to three times a week and, on each occasion, the reproductive status of the adult females encountered and identified were recorded. Altogether, 484 and 779 adult females were identified on Key Lois and Raccoon Key, respectively, that is, at least $95 \%$ of the free-ranging adult females on the islands. Identifications were made mostly by means of the animals' chest tattoos; the large number of females precluded recognition of all of them on the basis of their individual physiognomies alone.

The age distributions of the observed Lois and Raccoon females, as they existed at the beginning of 1992, are shown (Fig. 1). In 1992, there were more adult females aged 20 and older on Raccoon Key than there were females under the age of eight. On Key Lois, there were more females more than 20 years old than there were individuals under the age of 12 . The unusual age structures of the two island populations were the 
result of two factors. First, the fact that the islands were originally populated with over 1200 similarly aged animals ensured that many (about 15\%) would survive to enter their third decade of life at about the same time. Second, in accordance with the mandates of the Department of Environmental Protection of the State of Florida, the annual removal of most of the yearlings and juveniles on the islands has been the norm, and has been nearly exhaustive on Key Lois.

Individual identification of the adult males on the islands was impractical owing to the males' dense chest hair and hence, the illegibility of their tattoos. Their relative abundance was estimated by dividing the number of identified females on each island by the adult male:female ratios of the colonies. The ratios were derived from periodic counts of all adult males (that is, individuals more than 5 years old) and females within sight at a given location and time. These counts were conducted from late summer through early winter, that is, during the first half of the annual Key Lois and Raccoon Key mating seasons.

The 1992 adult male:female ratios for Key Lois and Raccoon Key were virtually identical: $1: 4.4$ and 1:4.6, respectively. In 1993, they were 1:4.2 and 1:4.1. Dividing the number of identified females on each island by the 1992 ratio yields adult male population estimates of 170 for Raccoon Key and 110 for Key Lois. During the 1993 counts, males were placed into one of three broad age categories: $5-12,13-19$ and $\geq 20$ years of age. In general, the age structures of the Raccoon Key and Key Lois males followed those of the females (Fig. Ib). For example, about $32 \%$ of the Lois females and $18 \%$ of the Raccoon females were over 20 years old in 1992, while the corresponding figures for the islands' males were estimated to be 26 and $17 \%$, respectively.

\section{Live birth rates}

When calculated on the basis of births that occurred during a single birth season, the live birth rate equals the number of live offspring born per adult female. When calculated on the basis of births that occurred during the 1992 and 1993 birth seasons combined, the live birth rate represents the number of live offspring born per female-year. A particular female was credited with having had a live birth if she was observed carrying or nursing a new-born during the birth season. However, any female bearing twin infants was credited with just one birth, while infants known to have died within $48 \mathrm{~h}$ of parturition were classed as stillborn.

Data collection was hindered by the observational conditions on the islands, and by the fact that, even after two years of field work, many of the monkeys remained difficult to approach and were identified only infrequently. Since determining the reproductive success of a female seen only occasionally was problematic, calculation of the live birth rates of the colonies was based solely on those females encountered and identified on more than 5 days during the months February-November. In 1992 and 1993, these months encompassed all but one extremely early birth (in January 1992). By restricting analyses to the animals seen on more than 5 days, the possibility of wrongly determining that a given female had not delivered a live infant when, in fact, she had, was minimized.

\section{Female body condition}

It is expected that the adiposity of a female macaque (i.e., energy reserves) reflect her overall nutritional status (Altmann and Alberts, 1987; Eley et al., 1989) and her ability to bear live young (van Schaik and van Noordwijk, 1985). Mass and adiposity measures were available for a number of Key Lois and Raccoon Key females. However, these animals did not constitute an unbiased sample of either population (Johnson and Kapsalis, 1995). Therefore, between-colony comparisons of the fatness of our subjects were made indirectly following the methods of Berman and Schwartz (1988). Specifically, the relative fatness of the subjects was assessed qualitatively. The animals were then assigned to one of four body condition categories: underweight, overweight, obese or within the normal weight range. The validity of our field judgements of the inter-individual differences in adiposity of the subjects is addressed elsewhere (Johnson and Kapsalis, 1995).

\section{Statistical analyses}

Least-squares regression was used to analyse the data on live birth rates. All frequency data (for example, the number of Lois and Raccoon females placed in each of the four body condition categories) were examined using the G-test with Williams' correction applied in all cases (see Sokal and Rohlf, 1981, for a discussion of these procedures).

\section{Results}

The age and number of the Key Lois and Raccoon Key females that were successfully identified on more than 5 days during the 1992 and 1993 birth seasons are provided (Table 1). Their age distributions reflect those of the Key Lois and Raccoon Key populations in their entirety (note the paucity of Lois females under the age of 10). Among these animals, the live birth rates for Key Lois and Raccoon Key (i.e. the total number of live births divided by the total number of female-years accumulated over both years of this study) were, respectively, 0.65 and 0.74 live offspring per female-year. These figures change little if the data are limited to those females identified on more than 10 days (Lois: 0.64 infants/female-year; Raccoon: 0.73 infants per female-year), or more than 20 days (Lois: 0.63; Raccoon: $0.76)$. Therefore, more than five identifications are considered sufficient to ascertain correctly the reproductive success of the vast majority of the Lois and Raccoon rhesus females.

Key Lois and Raccoon Key live birth rates were plotted as a function of female age (Fig. 2). However, data points based on fewer than 10 female-years were excluded and the data for ages 23 and 24 were pooled. The plot for Raccoon Key reveals that live birth rates increased with each year of life for females aged 4-8 years, but generally declined thereafter. Eight-year-old females exhibited the greatest fertility, producing 0.94 infants per female-year. In contrast, 23- and 24-year-old animals, together, produced just 0.42 young per female-year. Because the curve for Key Lois is incomplete it is concluded that female fertility on this island declined over the age range 10-24 years. Least-squares regressions fitted to the data points for females aged 8-24 years for Raccoon Key, and 10-24 years for Key 
Table 1. Number of Key Lois and Raccoon Key adult females observed more than five times from February to November 1992 and 1993, and the total number of live births and female-years recorded on both islands

Female age (years)

$\begin{array}{lllllllllllllllllllllll}4 & 5 & 6 & 7 & 8 & 9 & 10 & 11 & 12 & 13 & 14 & 15 & 16 & 17 & 18 & 19 & 20 & 21 & 22 & 23 & 24 & 25 & \text { Total }\end{array}$

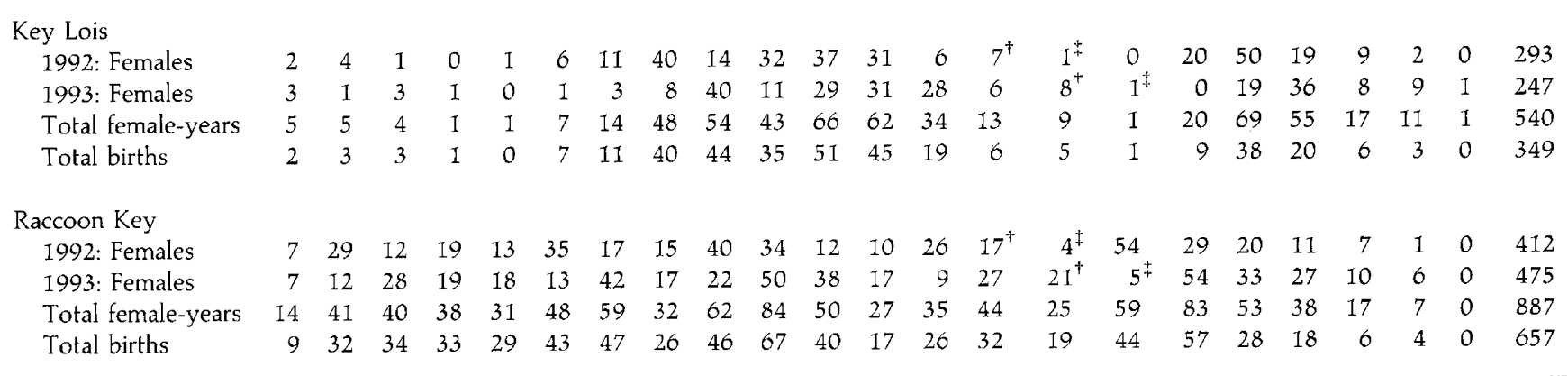

${ }^{\dagger}$ Oldest island-born females.

${ }^{\ddagger}$ Youngest Indian-born females.

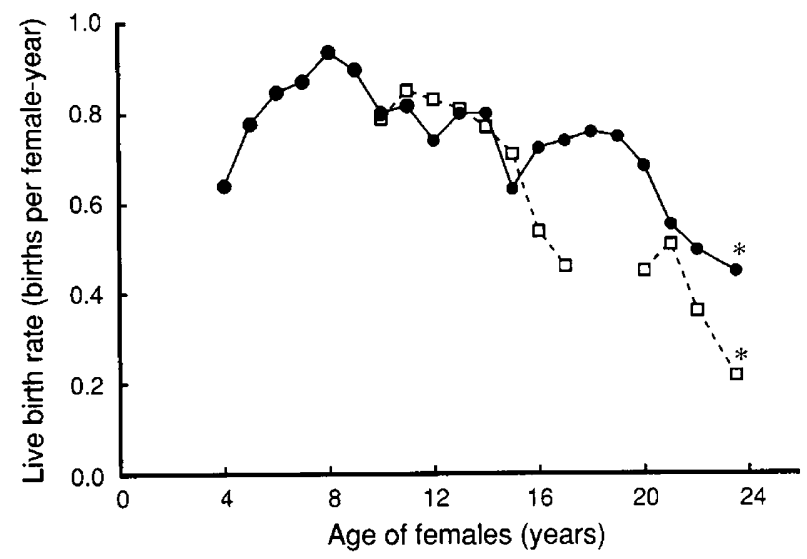

Fig. 2. Live birth rates of rhesus monkeys from (- - Key Lois and $(--\square--)$ Raccoon Key as a function of age of female rhesus monkeys. Each birth rate was calculated by dividing the total number of live infants born to females of a given age during 1992 and 1993 by the total number of female-years (for example, $11 / 14=0.79$ live births per female-year for 10-year-old females on Key Lois; see Table 1). *These final points were derived from the data of 23- and 24-year-old females collectively.

Lois, were both highly significant (Raccoon Key: $r=0.88$, $P<0.001, n=16$; Key Lois: $r=0.94, P<0.001, n=12$ ). Comparison of the Raccoon Key and Key Lois birth rate curves reveals unexpectedly that, while the Lois and Raccoon females 10-15 years of age produced live infants at about the same rate, Key Lois females, more than 16 years of age, consistently produced fewer live young than did their counterparts on Raccoon Key. As a consequence, the slope of the regression lines, fitted to the data points of each colony for females aged 10 years and above, differ significantly $(t=2.86$, d.f. $=23$, $P<0.01$ ).

The age-related variation in the fertility of animals, and the nature of the between-colony difference in live birth rates among females aged 16 years and older were explored further by examining individuals whose reproductive success for both
1992 and 1993 was known. Specifically, the proportion of the females on each island that successfully delivered a live infant during both 1992 and 1993 was compared with the proportion that produced none. The prevalence of annually reproducing and non-reproducing females was examined in four age groups. The first group encompassed the peak fertility years for rhesus females (6-9 years). The second group encompassed the age span wherein the Key Lois live birth rates approximately equalled those of Raccoon Key (10-15 years). The third group included females 16-19 years of age, the age span wherein the Raccoon Key and Key Lois live birth rates began to diverge, while the fourth was comprised of the unequivocally old animals, that is, females more than 20 years of age.

Of the Raccoon Key females, aged 6-9 years in 1992, 75\% (55 of 73) successfully reproduced in both years, and all these animals succeeded in bearing a live young in at least one year. The proportion of the Raccoon Key females that delivered live young in both years declined in each of the succeeding age groups, while the proportion of those who failed to bear a live infant in either year increased progressively (Fig. 3). The reproductive success in 1992 and 1993 of the Key Lois females, aged 6-9 years, is known for only four individuals, too small a sample on which to base meaningful comparative percentages. However, it is noteworthy that, like their same-aged counterparts on Raccoon Key, all four of these females succeeded in bearing a live young during one of the two birth seasons.

In the age group 10-15 years, the percentage of females that bore two successive infants or failed to reproduce at all was strikingly similar on Key Lois and Raccoon Key (Fig. 3). There was also inter-colony similarity in the reproductive success of females more than 20 years old, although this was limited to the proportion of females that failed to reproduce in either year. However, only about $24 \%$ (15 of 63 ) of the Lois females 20 years old and older gave birth during both 1992 and 1993, whereas $42 \%$ (23 of 55 ) did so on Raccoon Key, a difference that is significantly different $(G=4.38$, d.f. $=1$, $P<0.05$ ). 


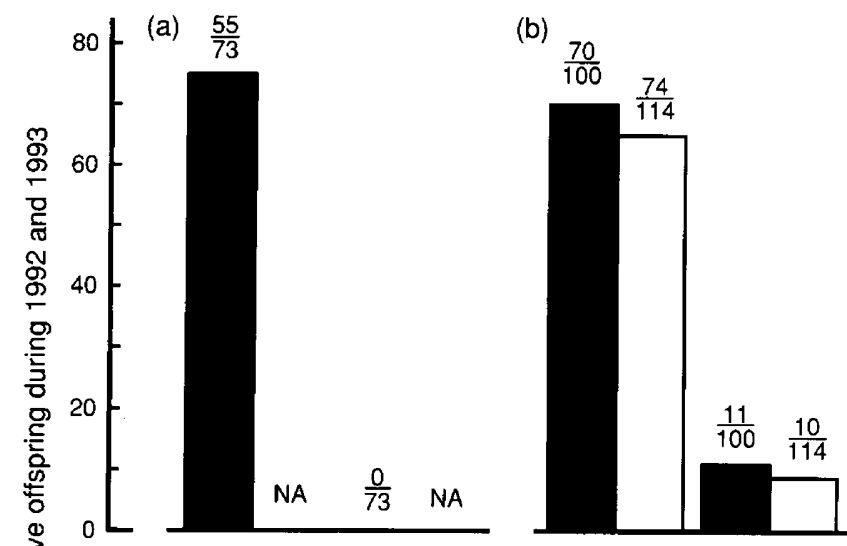

(c)

(d)
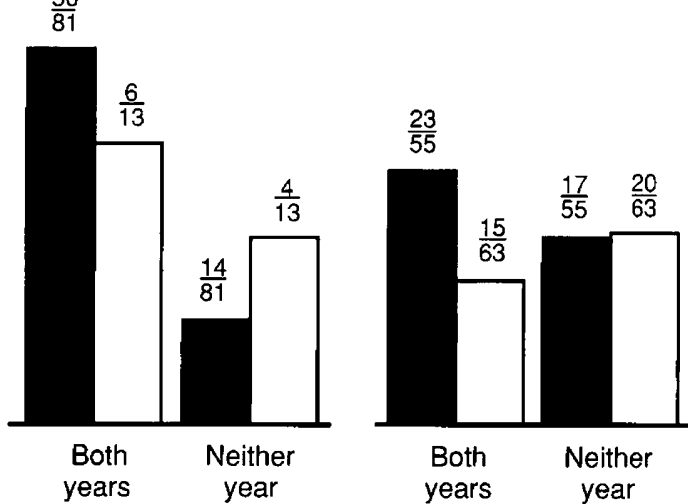

Fig. 3. Percentage of ( $\square$ ) Raccoon Key and $(\square)$ Key Lois female rhesus monkeys that bore live offspring during both years of this study or during neither year. Percentages are provided for each of four age categories: (a) 6-9 years old; (b) 10-15 years old; (c) 16-19 years old and (d) 20 years old and older. The ratios shown at the top of each bar represent the number of females upon which each percentage is based (the denominator is the total number of females within a given age category whose reproductive performance for both 1992 and 1993 was known). NA: There were insufficient Key Lois females aged 6-9 years to allow the calculation of meaningful percentages.

When compared with those on Key Lois, proportionately more of the Raccoon Key females in the 16-19 years group bore two consecutive infants and proportionately fewer failed altogether to deliver a live offspring (Fig. 3); however, this result is based on only $13 \mathrm{Key}$ Lois females and must, therefore, be interpreted with caution.

Taken together, these analyses indicate that the age-related decline in live birth rates that occurred among females more than eight years old was the result of two phenomena: (1) proportionately fewer older females bearing live young during successive birth seasons, and (2) proportionately more older females experiencing an inability to bear live young even after one or more barren years. These analyses further indicate that the inter-population difference in fertility seen in females more than 20 years old (Fig. 2) was the result of a between-colony difference in the proportion of annual reproducers, that is, females that produced offspring in both 1992 and 1993; the proportion of non-reproducing females was nearly identical on the two islands. A greater prevalence of annual reproducers on
Raccoon Key almost certainly also contributed to the interpopulation difference in live birth rates seen among 16- and 17-year-olds; but, it is unclear whether the large inter-colony difference in live birth rates that manifested itself among females of this age group may also have been the consequence of a greater prevalence of non-reproducers on Key Lois.

The 1993 trapping and removal of 1992 offspring cannot account for the greater proportion of annually reproducing aged females on Raccoon Key as the respective timings of the annual cycle of births and the removal of yearlings for sale guarantees that, on both islands, most females that reproduce two years in a row will be separated from their first offspring only after they have conceived their second. In fact, 17 of the 23 Raccoon Key females more than 20 years old that delivered live infants during both years of this study are known to have still had their 1992 offspring (and therefore were still lactating: Gomendio, 1989; Johnson et al., 1993) when they conceived their 1993 infants.

The observed inter-population difference in the reproductive performance of the older animals could not be attributed to an inter-colony difference in female body condition. During the mating season of 1992, 219 Key Lois and 368 Raccoon Key adult females were encountered frequently enough and under the right circumstances to be reliably placed in one of our four body condition categories. Proportionately more Raccoon Key females were classified as underweight, and proportionately more of the Key Lois females were categorized as either overweight, obese or within the normal weight range $(G=12.54$, d.f. $=3, P<0.025$ ) (Fig. 4). Among females more than 20 years of age (Fig. $4 \mathrm{~b}$ ), the proportion of overweight and obese animals appears to have been about the same on the two islands, but the inter-colony differences in the proportion of underweight individuals and individuals of normal body mass was even more disparate $(G=11.64$, d.f. $=3, P<0.025)$. These data indicate that the rhesus females on Key Lois (particularly those over 20 years old) were generally heavier, rather than lighter, than their counterparts on Raccoon Key, and presumably in better condition. In addition, irrespective of which category of body condition they were placed in during the 1992 mating season, the Key Lois females then 20 years old and older produced fewer infants per female in 1993 than did like-aged animals of similar body mass on Raccoon Key (Fig. 4c).

\section{Discussion}

On Raccoon Key, the probability of a successful delivery of a live offspring in 1992 and 1993 was greatest among those females that were 8 years of age, and generally declined with every additional year of life (as it did among females more than 10 years of age on Key Lois). The decline in female fertility was due to an increasing proportion of females experiencing successive barren years and a decreasing proportion of females experiencing successive fertile years. In 1986, the live birth rates of the Raccoon Key females 14-18 years of age (the oldest animals then present on either island) tended to be higher than those of their peers on Key Lois, but not conspicuously so (see Johnson, 1989, Fig. 1). However, in 1992 and 1993, there was a marked inter-colony difference in the live 

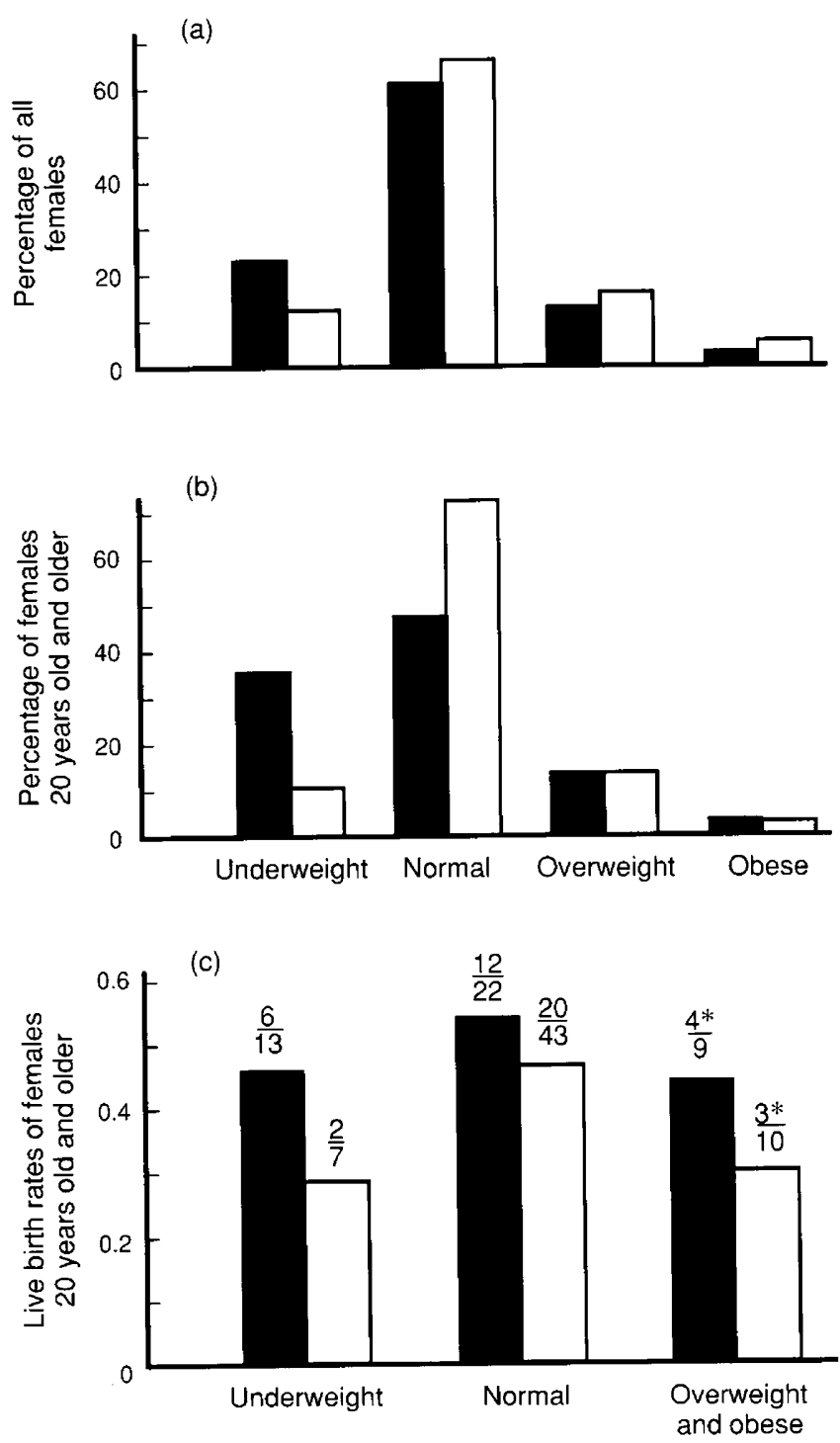

Fig. 4. Percentage of (a) all females or (b) those 20 years of age and older placed in each of the four body condition categories during the 1992 mating season, and (c) the 1993 live birth rates of the aged animals expressed as a function of their body condition ( $\boldsymbol{\square}$ ) Raccoon Key; ( $\square$ ) Key Lois. The ratios shown at the top of each bar in (c) represent the number of females upon which each birth rate is based (the denominator is the total number of females within a given body condition category whose reproductive performance for 1993 is known). *The data of the overweight animals were combined with those of the obese females because there are just four of the latter (two on Lois and two on Raccoon) whose reproductive performance in 1993 was known.

birth rates of females 16-24 years old; the reproductive performance of the Raccoon Key females was markedly higher. The inter-colony disparity in the live birth rates of the aged rhesus females (those more than 20 years of age) is a consequence of a larger proportion of such animals giving birth during both years of this study on Raccoon Key than on Key Lois.

Most females that successfully reproduced in 1992 (aged or not) were still nursing their infants after the subsequent mating season began. This is an important point since a suckling infant can reduce the number of ovulatory cycles a macaque female can potentially undergo during the mating season (Pope et al, 1986; Johnson et al., 1993; Mitsunaga et al., 1994) and thereby impair her ability to conceive. One explanation for the observation that females that bore live young during both 1992 and 1993 were proportionately most numerous among the 6to-9-year-olds and least numerous among the females 20 years old and older is that the inhibitory power of suckling is greater among those in the latter age categories.

The reason why so many of the old rhesus females on Raccoon Key were so much more successful than their peers on Key Lois at producing live young during both 1992 and 1993 is unknown. Several potential factors can be dismissed, however. First, the aged females on Raccoon Key did not reproduce more successfully because they were energetically advantaged relative to their counterparts on Key Lois; the relative adiposity of the subjects on Raccoon Key and Key Lois are inconsistent with this idea. Second, given that the founding populations of both island colonies were large and comprised animals originating from multiple localities in India, it is unlikely that the Raccoon females are genetically predisposed toward greater fertility because of a founder effect. Third, inasmuch as the aged females on Raccoon Key known to have successfully delivered two live infants were distributed among eight of the 12 social groups on the island, and inasmuch as the number of females in these eight groups ranged from 90 to 15 , it is unlikely that the reproductive success of the old Raccoon Key females can be attributed to any aspect of group size. Finally, female-female competition for access to males (which would be expected to intensify as the male:female ratio declines; see Dunbar and Sharman, 1983) is an unlikely explanation for the greater fertility of the Raccoon Key females since the adult sex ratio on Raccoon Key is indistinguishable from that on Key Lois (see Methods). Furthermore, there were few females in their peak fertility years on Key Lois. Hence, the reproductive performance of the aged Lois females did not suffer because of greater inter-generational, female-female competition for males as mates.

We consider the greater prevalence of annually reproducing older females on Raccoon Key to be a consequence of one or both of the following factors: (1) the overall agedness of the adult males on Key Lois, and (2) the consumption of fecundity-promoting phytochemicals present in the natural vegetation of the islands. The first of these explanations assumes that fertility in male rhesus monkeys declines with age (as it does in men; see Murray and Meacham, 1993), and that a mating between an aged female and an older male is particularly unikely to culminate in a live-birth conception. The second explanation assumes that, since the diversity of plant species on Raccoon Key is greater than that on Key Lois, the range of phytochemicals consumed by the Raccoon monkeys differs from that of their Key Lois counterparts. It further assumes that one or more factors within the plant foods eaten by the Raccoon Key monkeys preferentially enhances the fertility of older females. It has yet to be demonstrated that the consumption of any phytochemical does promote fecundity in female primates of any age (but see Whitten, 1982, 1983; Garey, 1991). Nevertheless, we feel the possibility must be entertained that the reproductive success of the aged rhesus 
females on Raccoon Key is due in part to the plants that they eat.

Even fully fecund female rhesus monkeys can be expected occasionally to experience successive barren years. However, none of the Lois or Raccoon subjects aged 6-9 years failed to reproduce during both 1992 and 1993, while many older animals did (especially those over 20 years old). We conclude that, in most cases, failing to reproduce for two consecutive years is indicative of an age-related diminution in the capacity to produce a live-birth conception, a diminution that is unrelated to lactation. Further, since non-reproducing females were proportionately as common on Raccoon Key as on Key Lois among the 10-15 and 20-24-year-old animals, we also conclude that the non-lactational loss of fecundity is no more prevalent on one island than it is on the other. Such would be the case if the risk of a fecundity loss increases with each additional year of life or the cumulative 'wear and tear' associated with repeated parturitions. In fact, previous research has already shown that both age (van Wegenen, 1972; Hodgen et al., 1977; Graham et al., 1979) and parity (McCann and Myers, 1970; Bertens et al., 1982) are associated with a deterioration of the reproductive capacity of female macaques.

Finally brief consideration should be given to the implications of our data for the occurrence of menopause in female rhesus monkeys. On both Key Lois and Raccoon Key, approximately $70 \%$ of the aged females whose reproductive success for both 1992 and 1993 is known (43 of 63 on Key Lois; 38 of 55 on Raccoon Key; see Fig. 3) were clearly not sterile since they successfully gave birth at least once during the course of this study. In contrast, sterility among aged women is nearly universal, since the cessation of ovulation in women typically occurs around age 50, that is, well before old age (Gosden, 1985). If true menopause does occur in free-ranging rhesus monkeys, our data demonstrate that it must happen very late in life for most of the Raccoon and Lois females. In fact, it is questionable whether a meaningful proportion of the females on either island will live long enough to experience it. Indeed, very old rhesus females may cease to ovulate (Hodgen et al., 1977; Walker, 1995), even within free-ranging populations (Malik and Johnson, 1992). However, we concur with Pavelka and Fedigan (1991) that, from a life history perspective, the rhesus female is an inappropriate model for human menopause.

The authors wish to thank P. Schilling for the opportunity to carry out research on Key Lois and Raccoon Key, and colony personnel for their co-operation and assistance. S. Shideler, R. Rawlins and M. Kessler provided helpful comments on an earlier draft of this paper. This work was conducted while R. L. Johnson was supported as a consultant to Charles River Laboratories which owns and manages the Key Lois and Raccoon Key rhesus colonies.

\section{References}

Altmann J and Alberts S (1987) Body mass and growth rates in a wild primate population Oecologia 72 15-20

Berman CM and Schwartz S (1988) A nonintrusive method for determining relative body fat in free-ranging monkeys American Journal of Primatology 14 53-54

Bertens AP, Helmond FA and Hein PR (1982) Endometriosis in rhesus monkeys Laboratory Animals 16 281-284
Biggers JD (1988) Fecundability Annals of the New York Academy of Sciences $541706-714$

Dunbar RIM and Sharman M (1983) Female competition for access to males affects birth rate in baboons Behavioral Ecology and Sociobiology 13 157-159

Eley RM, Strum SC, Muchemi G and Reid GDF (1989) Nutrition, body condition activity patterns, and parasitism of free-ranging troops of olive baboons (Papio anubis) in Kenya American Journal of Primatology 18 209-220

Fedigan L (1991) Life span and reproduction in Japanese macaque females. In The Monkeys of Arashiyama: Thirty-five Years of Research in Japan and the West pp 140-154 Eds LM Fedigan and PJ Asquith. State University of New York Press, Albany

Garey JD (1991) Acacia flowers from wild vervet diets are reproductive stimulators American Journal of Primatology 24 102-103

Gomendio M (1989) Suckling behaviour and fertility in rhesus macaques (Macaca mulatta) Journal of Zoology 217 449-467

Gordon TP (1981) Reproductive behavior in the rhesus monkey: social and endocrine variables American Zoologist 21 185-195

Gosden MG (1985) Biology of Menopause. Academic Press, London

Graham CE, Kling OR and Steiner RA (1979) Reproductive senescence in female nonhuman primates. In Aging in Nonhuman Primates pp 183-209 Ed. DJ Bowden. Van Nostrand Reinhold, New York

Hodgen GD, Goodman AL, O'Connor A and Johnson DK (1977) Menopause in rhesus monkeys: model for study of disorders in the human climacteric American Journal of Obstetrics and Gynecology 127 581-584

Hrdy SB (1981) 'Nepotists' and 'altruists': the behavior of old females among macaques and langur monkeys. In Other Ways of Growing Old pp 59-76 Eds PT Amoss and S Harrell. Stanford University Press, Stanford

Johnson PL, Wood JW and Weinstein M (1990) Female fecundity in highland New Guinea Social Biology 37 26-43

Johnson RL (1989) Live birthrates in two free-ranging rhesus breeding colonies in the Florida Keys Primates 30 433-437

Johnson RL and Kapsalis E (1995) Determinants of postnatal weight in infant rhesus monkeys: implications for the study of interindividual differences in neonatal growth American Journal of Physical Anthropology 98 344-354

Johnson RL, Berman CM and Malik I (1993) An integrative model of the lactational and environmental control of mating in female rhesus monkeys Animal Behaviour 46 63-78

Lehman SM, Taylor LL and Easley S (1994) Climate and reproductive seasonality in two free-ranging island populations of rhesus macaques (Macaca mulatta) International journal of Primatology 15 115-128

McCann TO and Myers RE (1970) Endometriosis in rhesus monkeys American Journal of Obstetrics and Gynecology 106 516-523

Malik I and Johnson RL (1992) Reproductive maturation and senescence in female rhesus: observations from Tughlaqabad, India Primate Report $\mathbf{3 4}$ 25-32

Menken J, Trussell J and Larsen U (1986) Age and infertility Science 233 $1389-1394$

Mitsunaga F, Nozaki M and Shimzu K (1994) Suppressed copulatory behavior and ovarian function in lactating Japanese monkeys (Macaca fuscata fuscata) during the mating season Primates 35 79-88

Murray MJ and Meacham RB (1993) The effect of age on male reproductive function World Journal of Urology 11 137-140

Paul A, Kuester J and Podzuweit D (1993) Reproductive senescence and terminal investment in female Barbary macaques International Journal of Primatology 14 105-124

Pavelka MSM and Fedigan LM (1991) Menopause: a comparative life history perspective Yearbook of Physical Anthropology 34 13-38

Pope NS, Gordon TP and Wilson ME (1986) Age, social rank and lactational status influence ovulatory patterns in seasonally breeding rhesus monkeys Biology of Reproduction 35 353-359

Pucak GJ, Foster HL and Balk MW (1982) Key Lois and Raccoon Key: Florida islands for free-ranging rhesus monkey breeding programs Journal of Medical Primatology 11 199-210

Sherman B (1980) The formation of relationships based on sociospatial proximity in a free-ranging colony of rhesus monkeys Primates 21 $484-491$

Silk J, Short J, Roberts J and Kusnitz J (1993) Gestation length in rhesus macaques (Macaca mulatta) International Journal of Primatology $\mathbf{1 4}$ 95-104

Sokal RR and Rohlf FJ (1981) Biometry pp 735-738 W. H. Freeman, New York 
van Schaik CP and van Noordwijk MA (1985) Interannual variability in fruit abundance and the reproductive seasonality in Sumatran long-tailed macaques (Macaca fascicularis) Journal of Zoology 206 533-549

van Wegenen G (1972) Vital statistics from a breeding colony: reproduction and pregnancy outcome in Macaca mulatta Journal of Medical Primatology 1 $3-28$

Walker ML (1995) Menopause in female rhesus monkeys American Journal of Primatology 35 59-71
Whitten PL (1982) Female Reproductive Strategies Among Vervet Monkeys PhD Thesis, Harvard University

Whitten PL (1983) Females, flowers and fertility American Journal of Physical Anthropology 60 269-270 (Abstract)

Wilson ME, Gordon TP and Collins DC (1982) Age differences in copulatory behavior and serum $17 \beta$-estradiol in female rhesus monkeys Physiology and Behavior 28 733-737 